
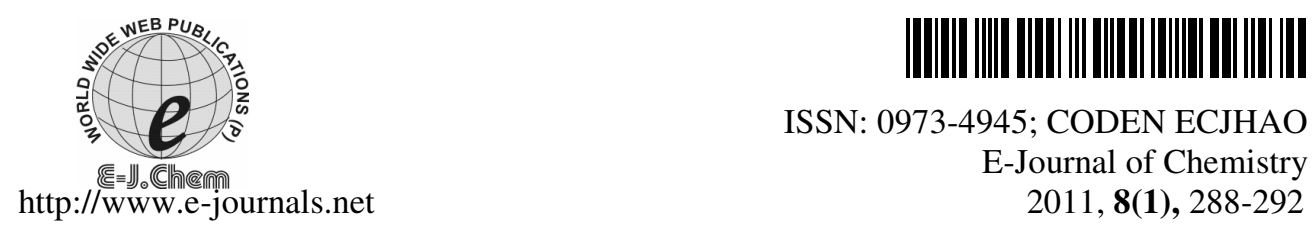

ISSN: 0973-4945; CODEN ECJHAO

E-Journal of Chemistry 2011, 8(1), 288-292

\title{
Microwave Promoted Regeneration of Carbonyl Compounds from Oximes Using $N, N$-Dichloro Poly(Styrene-co-divinylbenzene)Sulphonamide Resin
}

\author{
A.G. BELDAR and MAMTA SHARMA* \\ Synthetic Chemistry Division \\ Defence R \& D Establishment, Jhansi Road, Gwalior- 474002, M.P., India \\ reekana@rediffmail.com
}

Received 10 May 2010; Accepted 20 July 2010

\begin{abstract}
An efficient, economically viable and operationally simple method was developed for deoximation of oximes (of ketones and aldehydes) to their corresponding carbonyl compounds using polymer beads of $N, N$-dichloro poly(styrene-co-divinylbenzene)sulphonamide resin. Polymeric reagent offered speedy conversion and substantial yields of products under mild condition and is recyclable. Deoximation was monitored by the use of ${ }^{13} \mathrm{C}$ NMR.
\end{abstract}

Keywords: Deoximation, $N, N$-dichloro poly(styrene-co-divinylbenzene)sulphonamide, Solid phase reagent, Resin.

\section{Introduction}

Oximes play a significant role in the organic synthesis as carbonyl group protector and enable the isolation and purification of ketoximes and aldoximes by selectively protecting them $^{1-17}$. A plethora of papers in the literature reveals the interest of researchers towards the rapid development of novel techniques for regeneration of carbonyl compounds from oximes under the mild conditions.

A wide variety of deoximation reagents have been developed so far such as manganese triacetate $^{18}$, dinitrogen tetraoxide ${ }^{19}$, trimethylsilyl chlorochromate ${ }^{20}$, titanium silicalite ${ }^{21}$, pyridinium chlorochromate ${ }^{22}$, bismuth trichloride ${ }^{23}$, ammonium persulfate- silica gel $^{24}$, sodium periodate ${ }^{25}$. Among them some require strong acidic condition; some takes long reaction time and give low product yield while some are poisonous and oxidative reagents posses serious isolation difficulties.

Heterogenised reagents ${ }^{26-28}$ has evinced the attention of researchers because of their handling ease, lower toxicity, non explosive and malodorous nature. Another important motive of supported reagents is facile isolation of the pure product than their solution phase equivalents. Few reports are available on the solid supported deoximating agents under mild condition ${ }^{29,30}$. 
$\mathrm{N}$-halo reagents are widely used in fine organic synthesis because of its highly reactive $\mathrm{N}-\mathrm{X}$ bond and various mode of its splitting. This polymeric resin proved to be a very strong chlorinating agent and found to be easily regenerable and reusable. In earlier work $N, N$-dichloro poly(styrene-co-divinylbenzene)sulphonamide has been reported as decontaminant ${ }^{31}$ and as chlorinating reagent for synthesis of dialkyl chlorophosphates ${ }^{32}$. This development encouraged us to explore the utility of polymeric beads in multi-dimensions. Here we report an organic transformation: a conventional and microwave assisted clean, rapid and efficient method for the regeneration of carbonyl compounds with the help of beads.

\section{Experimental}

IR spectra were recorded on FT-IR spectrometer Perkin-Elmer model 1720 on KBr disk. (for solids) and neat for liquids. ${ }^{13} \mathrm{C}\left\{{ }^{1} \mathrm{H}\right\}$ NMR spectra were recorded in $\mathrm{CDCl}_{3}$ solvent on Bruker DPX Advance FT-NMR instrument at $400 \mathrm{MHz}$ and $100 \mathrm{MHz}$ respectively using trimethylsilane as an internal standard at $0.0 \mathrm{ppm}$. A house hold LG make oven was used for studies.

\section{General procedure for deprotection of oximes}

A mixture of oxime $(2 \mathrm{mmol})$, carbon tetrachloride $(8 \mathrm{~mL})$ and $N, N$-dichloro poly(styrene-codivinylbenzene)sulphonamide resin $(2 \mathrm{mmol})$ was refluxed or irradiated in the microwave oven at power $600 \mathrm{~W}$ for specific time period (Table 1). When all the oxime was converted, the intermediate was hydrolysed by adding water and washed with $\mathrm{CCl}_{4}$. Before adding $\mathrm{CCl}_{4}$ beads were separated out through filtration. The organic layer was dried with $\mathrm{MgSO}_{4}$ after separation from aqueous layer. Carbon tetrachloride was evaporated to get desired product. The yield and ${ }^{13} \mathrm{C}$ NMR chemical shift values are summarized in the Table 1 and 2 respectively.

Table 1. Deoximation with $N, N$-dichloro poly(styrene-co-divinylbenzene)sulphonamide produced via Scheme 1

\begin{tabular}{|c|c|c|c|c|c|c|c|}
\hline Entry & Product $^{\mathrm{a}}$ & $\begin{array}{l}\text { Time Reflux }{ }^{\mathrm{b}} / \\
\text { M.W. }\end{array}$ & $\begin{array}{c}\text { Yield, } \\
\%\end{array}$ & Entry & Product $^{\mathrm{a}}$ & $\begin{array}{l}\text { Time Reflux }{ }^{\mathrm{b}} / \\
\text { M.W. }\end{array}$ & $\begin{array}{c}\text { Yield } \\
\%\end{array}$ \\
\hline 1 & & $55 / 60$ & 96 & 9 & & $65 / 120$ & 81 \\
\hline 2 & & $50 / 60$ & 92 & 10 & & $75 / 90$ & 89 \\
\hline 3 & & $75 / 90$ & 89 & 11 & & $75 / 120$ & 85 \\
\hline 4 & & $65 / 90$ & 90 & 12 & & $55 / 90$ & 82 \\
\hline 5 & & $90 / 120$ & 91 & 13 & & $65 / 90$ & 88 \\
\hline 6 & & $65 / 90$ & 91 & 14 & & $70 / 120$ & 76 \\
\hline 7 & & $50 / 90$ & 85 & 15 & & $70 / 90$ & 79 \\
\hline 8 & & $60 / 90$ & 90 & 16 & & $50 / 60$ & 86 \\
\hline
\end{tabular}

M.W.=Microwave, ${ }^{a}$ Products were characterized by their physical properties, comparison with authentic samples and IR spectra. ${ }^{b}$ time in minutes. ${ }^{C}$ time in seconds 


\section{Results and Discussion}

The microwave energy has given a new dimension and vision to organic reactions ${ }^{29}$. The reaction of oximes with polymeric reagent in $\mathrm{CCl}_{4}$ provide carbonyl compound without any side product, under the microwave radiations (Scheme 1). The completion time of reaction was monitored by TLC and ${ }^{13} \mathrm{C}\left\{{ }^{1} \mathrm{H}\right\}$ NMR spectroscopy.

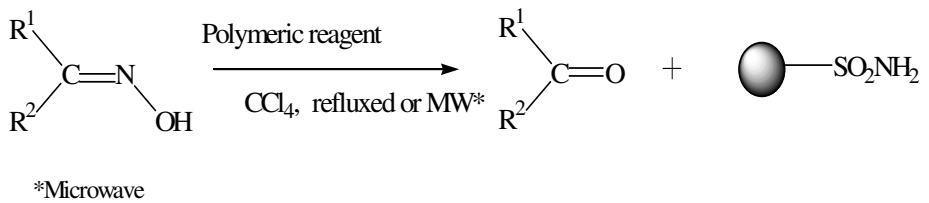

\section{Scheme 1}

We obtained almost all quantitative yields in short reaction times. The microwave temperature for the reaction of various oximes with $N, N$-dichloro poly(styrene-codivinylbenzene)sulphonamide polymeric beads afforded the corresponding carbonyl compounds in 55 to $90 \mathrm{sec}$. in excellent yields (Scheme 1, Table 1).The uniqueness of this method is its simplicity and time saving. The process of a typical reaction was monitored by appearance and disappearance of ${ }^{13} \mathrm{C}$ NMR signal of carbonyl and oximino carbon respectively (Figure 1).
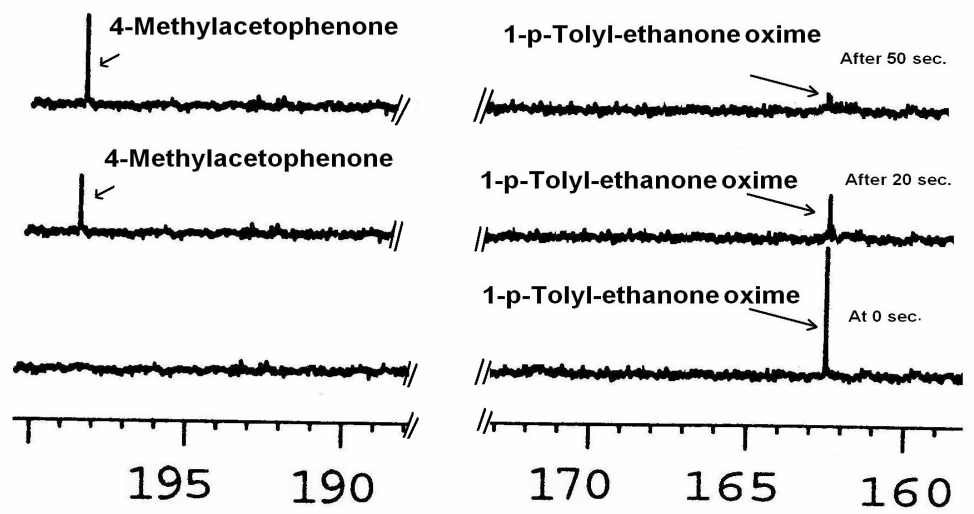

Figure 1. Progress of a typical reaction as monitored by ${ }^{13} \mathrm{C}\left\{{ }^{1} \mathrm{H}\right\}$ NMR analysis at different time intervals for entry 2.

Reason behind the use of NMR is here, that it provides direct analysis of reaction mixture without the use of any tedious sample preparation method as it is required in GC-MS. The carbon chemical shift changes with significant difference $(\sim \Delta \delta=35 \mathrm{ppm})$ on conversion of oxime ( $\delta$ range of $\mathrm{C}=\mathrm{N}$ is $145-170 \mathrm{ppm}$ ) into carbonyl ( $\delta$ range of $\mathrm{C}=\mathrm{O}$ is $190-227 \mathrm{ppm}$ ). ${ }^{13} \mathrm{C}\left\{{ }^{1} \mathrm{H}\right\}$ NMR chemical shifts of oximes and carbonyl compounds are presented in the Table 2 . The results of conversion of oximes to their corresponding carbonyl compounds are presented in the Table 1. In order to evaluate the generality and applicability of this method a variety of oximes were deprotected to their parent carbonyl compounds. The product of reaction with polymeric reagent was isolated simply by filtering off the solid polymer and subsequently evaporation of the solvent from filtrate. The advantages of this method are good yield, mild condition, short reaction time and no side product. The recovered polymer was again chlorinated and reused up to several times without any loss in activity. 
Table 2. ${ }^{13} \mathrm{C}\left\{{ }^{1} \mathrm{H}\right\}$ NMR chemical shifts of compounds

\begin{tabular}{cccccc}
\hline Entry & $\begin{array}{c}{ }^{13} \text { C NMR values } \\
\text { of carbonyl } \\
\text { carbon }\end{array}$ & $\begin{array}{c}{ }^{13} \text { C NMR } \\
\text { values of } \\
\text { oximino carbon }\end{array}$ & Entry & $\begin{array}{c}{ }^{13} \mathrm{C} \text { NMR values } \\
\text { of carbonyl } \\
\text { carbon }\end{array}$ & $\begin{array}{c}{ }^{13} \mathrm{C} \text { NMR } \\
\text { values of } \\
\text { oximino carbon }\end{array}$ \\
\hline 1 & 197.1 & 162.3 & 8 & 212.7 & 173.6 \\
2 & 198.61 & 162.2 & 9 & 217.2 & 163.7 \\
3 & 195.89 & 162 & 10 & 217.1 & 169.9 \\
4 & 201.1 & 160.4 & 11 & $217.8 * 201.2$ & 164.8163 .2 \\
5 & 207.8 & 163.8 & 12 & 192 & 151.9 \\
6 & 194.5 & 163.9 & 13 & 210.7 & 145.1 \\
7 & 209.7 & 160.5 & 14 & 212.3 & 142.6 \\
\hline 8 & 192.6 & 161.9 & 15 & 216.1 & 144.7 \\
\hline
\end{tabular}

${ }^{a}$ Chemical shift of carbonyl carbon in ppm, ${ }^{*}$ acetyl group, ${ }^{b}$ chemical shit of oximino carbon in ppm

\section{Conclusion}

In conclusion, $N, N$-dichloro poly(styrene-co- divinylbenzene)sulphonamide resin is a efficient reagent to fulfil different required objectives of organic synthesis. Here in this work it is proved to be an important and valuable reagent for the conversion of oximes to their corresponding carbonyl compounds. The conversion was very efficient, with excellent yield, and polymeric reagent can be recovered, activated and reused. The main advantage of the method is that reactions were very clean and operationally simple. Therefore method is attractive for organic chemist.

\section{Acknowledgment}

Authors are thankful to Dr. R. Vijayaraghavan, Director Defence Research \& Development Establishment (DRDE) Gwalior.

\section{References}

1. Firouzabadi H and Jafari A A, J Iranian Chem Soc., 2005, 2, 85.

2. Greene T.W and Wuts P G M, Protective Groups in Organic Synthesis; $3^{\text {rd }}$. Ed.; John Wiley, New York, 1999, p. 355.

3. Wang E C, Huang K S, Chen H M, Wu C C and Lin G J, J Chin Chem Soc., 2004, 51, 619-627.

4. Green T W and Wuts P G M, Protective Groups in Organic Synthesis $2^{\text {nd }}$ Ed., Wiley, New York, 1991, p. 172.

5. Bandgar B P, Lalita B K and Thote J L, Synth Commun., 1997, 27, 1149-1152.

6. Goswami P and Chowdhury P K, Indian J Chem., 2001, 40B, 156-158.

7. Edmont D and Williams D.M, Tetrahedron Lett., 2000, 41, 8581-8586.

8. Mikshiev Y M, Kornilov V I, Paidak B B and Zhdanov Y A, Russ J Gen Chem., 1999, 69, 476-482.

9. Mira C and Shlomo R, Tetrahedron Lett., 2006, 47, 763-766.

10. Corsaro A, Chiacchio U and Pistara V, Synthesis, 2001, 13, 1903.

11. Gholizadeh M and Mohammadpoor B I, Bull Korean Chem Soc., 2005, 26, 1836-1838.

12. Balachander N, Wang S S and Sukenik C N, Tetrahedron Lett., 1986, 27, 4849-4852.

13. Demir A S, Tanyeli C and Altinel E, Tetrahedron Lett., 1997, 38, 7267.

14. Chaudhari S S and Akamanchi K G, Tetrahedron Lett., 1998, 39, 3209. 
15. Chrisman W, Blankinship M J, Taylor B and Harris C E, Tetrahedron Lett. 2001, 42, 4775-4777.

16. Hajipour A R, Mallakpour S E, Baltork I M and Abibi H, Synth Commun., 2001, 31, 3401-3409.

17. Shirini F, Mamaghani M, Parsa F and Mohammadpoor B I, Bull Korean Chem Soc., 2002, 23(11), 1683-1684.

18. Demir A.S, Tanyeli C and Altinel E, Tetrahedron Lett., 1997, 38(41), 7267-7270.

19. Shim S B, Kim K and Kim Y H, Tetrahedron Lett., 1987, 28(6), 645-648.

20. Aizpurua J.M, Juaristi M, Lecea B and Palomo C, Tetrahedron, 1985, 41, 2903.

21. Joseph R, Sudalai A and Ravindranathan T, Tetrahedron Lett., 1994, 35, 5493-5496.

22. Maloney J R, Lyle R E and Savendra J E and Lyle G G, Synthesis, 1978, 212.

23. Baruah A, Boruah B, Prajapati D and Sandhu J S, Tetrahedron Lett., 1997, 38(43), 4267-4268.

24. Verma R S and Meshram H M, Tetrahedron Lett., 1997, 38, 5427.

25. Verma R S, Dahiya R and Saini R.K, Tetrahedron Lett., 1997, 38, 8819-8820.

26. Pandey L K, Pathak U and Rao A N, Synth Comm., 2007, 37, 4105-4109.

27. Pathak U, Pandey L K and Tank R, J Org Chem., 2008, 73, 2890-2893.

28. Zolfigol M A, Bagherzadeh M, Chehardoli G, Mallakpour S E and Mamaghani M, $J$ Chem Res(S), 2001, 390-393.

29. Khazaei A and Vaghei R G, Tetrahedron Lett., 2002, 43, 3073-3074.

30. Khazaei A, Mallakpour S and Vaghei R G, Iranian Polymer J., 2003, 12(2), 115-118.

31. Gutch P K, Shrivastava R K and Dubey D K, J Appl Polym Sci., 2006, 105(4), 2203-2207.

32. Gupta H.K, Mazumdar A, Garg P, Gutch P K and Dubey D K, Tetrahedron Lett., 2008, 49, 6704-6706. 


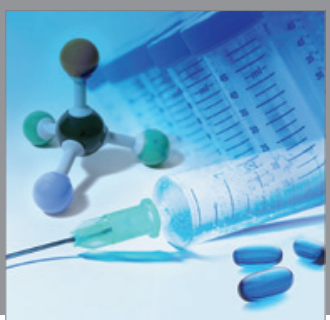

International Journal of

Medicinal Chemistry

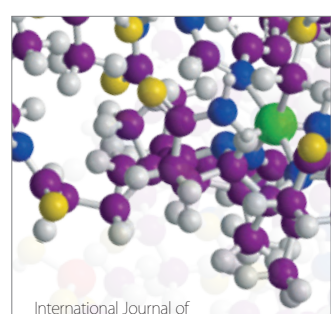

Carbohydrate Chemistry

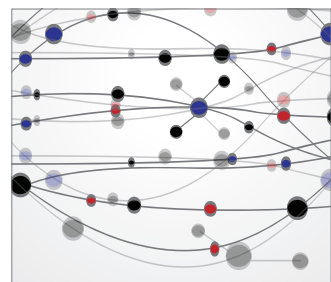

The Scientific World Journal
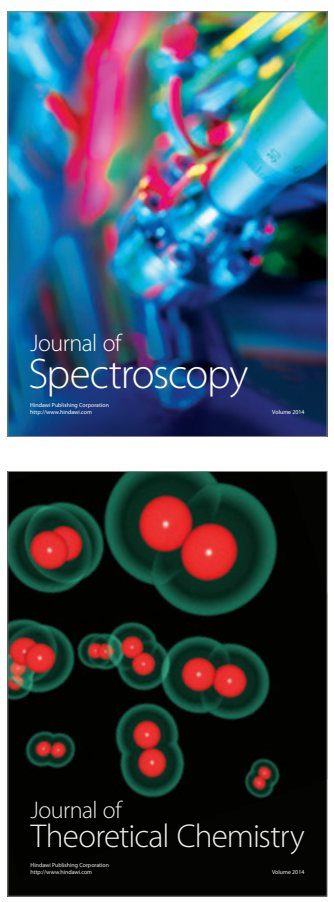
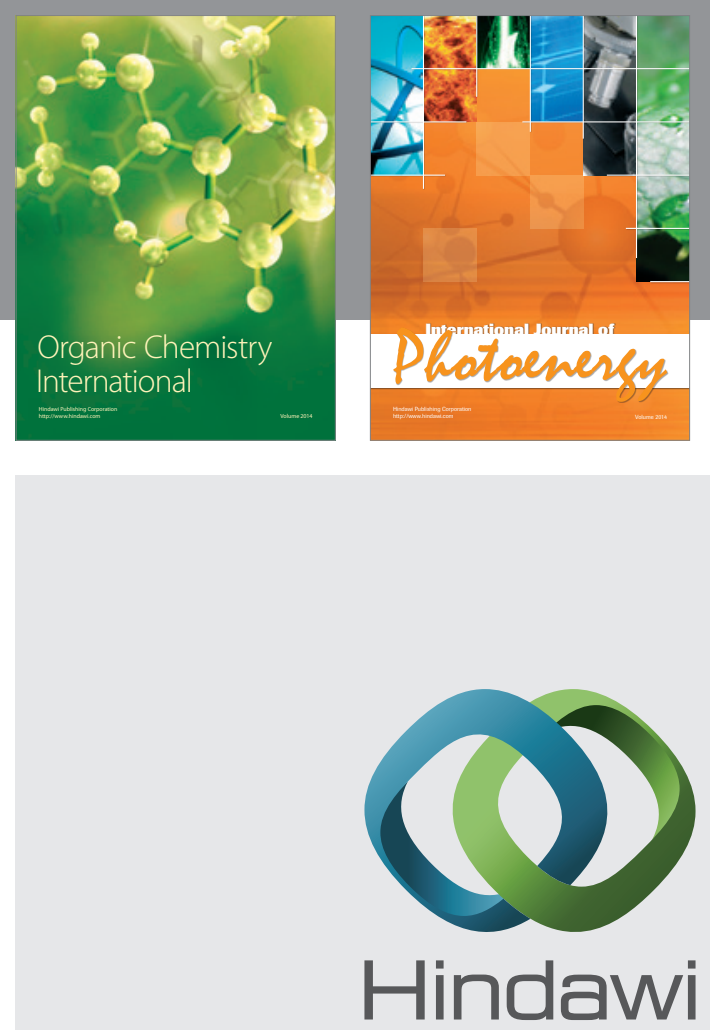

Submit your manuscripts at

http://www.hindawi.com
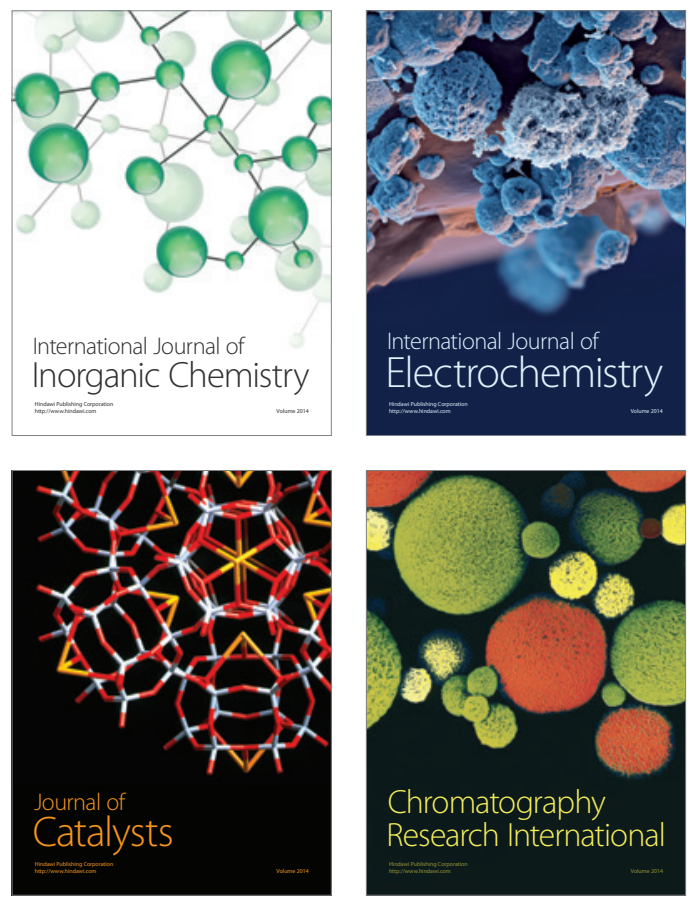
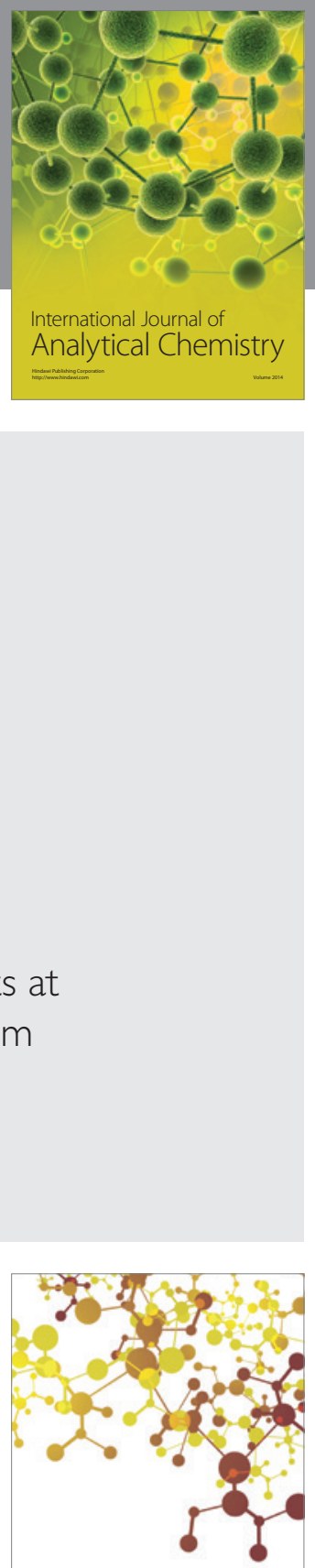

Journal of

Applied Chemistry
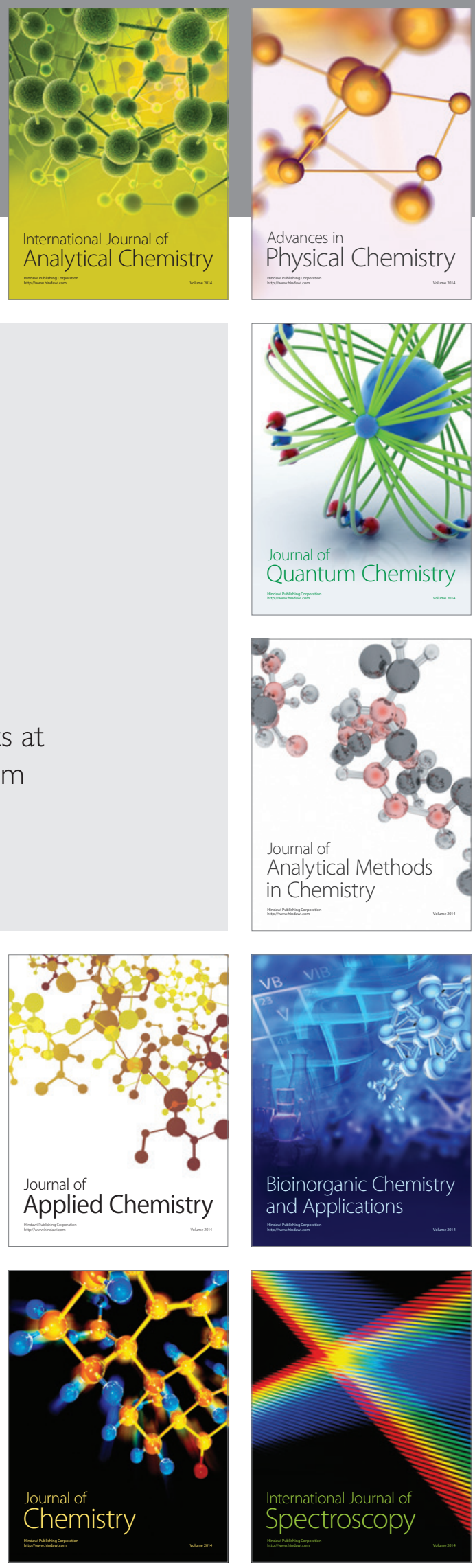